\title{
0 PACTO EDUCATIVO PARA 0 FUTURO: UM INSTRUMENTO ESTRATÉGICO PARA 0 DESENVOLVIMENTO EDUCATIVO EM PORTUGAL ${ }^{1}$
}

\section{Ana Benavente (*)}

SÍNTESE: Este texto apresenta o Pacto educativo para o futuro proposto pelo governo do partido socialista eleito em 1995 em Portugal. 0 atraso educativo do país nos últimos séculos e as sucessivas rupturas nas políticas educativas desde a revolução democrática de 1974, levaram o governo a propor um Pacto a todos os parceiros sociais e educativos. Considerando que a educação é um "assunto de todos» e que as mudanças exigem uma participação alargada para o desenvolvimento da educação e a melhoria da sua qualidade, iniciou-se um amplo debate centrado na educação como «uma paixão e uma ambição». O Pacto explicitava orientações, objectivos estratégicos e compromissos imediatos, e propunha-se constituir uma carta de referência para todos os parceiros educativos. Numa lógica de «geometria variável», procuravam-se acordos, parcerias e coordenação de esforços para o desenvolvimento educativo. Os mal-entendidos, obstáculos e desacordos levaram ao insucesso deste processo, embora tenha havido, também, consequências positivas (em protocolos celebrados e em maior participação social na educação, nomedamente).

Tendo a autora feito parte da equipa política do Ministério da Educação entre 1995 e 2001, explicita, neste artigo, os objectivos do Pacto, a estratégia seguida, bem como os aspectos positivos e negativos mais importantes do processo social então vivido, ensaiando uma primeira avaliação crítica.

SÍNTESIS: Este texto presenta el Pacto educativo para el futuro propuesto por el gobierno del partido socialista electo en 1995 en Portugal. El atraso educativo del país en los últimos siglos y las sucesivas rupturas en las políticas educativas desde la revolución democrática de 1974, Ilevaron al

${ }^{1}$ Este texto retoma, em parte, um documento de trabalho por mim elaborado para o BIE/UNESCO, em 2003, no quadro da formação interdisciplinar para o diálogo político.

(*) Secretária de Estado da Educação entre 1995 e 2001. Deputada e investigadora na Universidade de Lisboa. 
gobierno a proponer un Pacto a todos sus pares sociales y educativos. Considerando que la educación es un "asunto de todos» y que los cambios exigen una participación amplia para el desarrollo de la educación y la mejora de su calidad, se inició un gran debate centrado en la educación como "una pasión y una ambición». El Pacto detallaba orientaciones, objetivos estratégicos y compromisos inmediatos, y proponía constituir una carta de referencia para todos los pares educativos. En una lógica de "geometría variable», se buscaban acuerdos, asociaciones y coordinación de esfuerzos para el desarrollo educativo.

Los desentendimientos, obstáculos y desavenencias llevaron al fracaso de este proceso, aunque hubo también consecuencias positivas (en protocolos celebrados y en mayor participación social en la educación, expresamente).

El hecho de que la autora formara parte del equipo político del Ministerio de la Educación desde 1995 hasta 2001, le permite explicar en este artículo los objetivos del Pacto, la estrategia seguida, así como los aspectos positivos y negativos más importantes del proceso social entonces vivido, ensayando una primera evaluación crítica.

\section{O CONTEXTO}

\subsection{ATRASO EDUCATIVO PORTUGUÊS}

Portugal vive uma situação singular entre os países da União Europeia; os indicadores nacionais e internacionais revelam níveis de educação e de formação da população muito inferiores aos dos outros países europeus; trata-se de uma fragilidade individual e colectiva com pesadas consequências económicas e sociais.

O déficit educativo português tem a ver, em grande parte, com as opções do «Estado Novo», regime autoritário que dominou o país entre 1926 e 1974, data da revolução dos "cravos», e que considerava a educação e a cultura um "perigo» para o povo. Debates na Assembleia Nacional, nos anos 30, revelam argumentos contrários à alfabetização, questionando: "aprender a ler, para quê? Para lerem panfletos e ideias erradas?».

Em meados do século XIX, em Portugal, país rural e católico, havia mais de $80 \%$ de analfabetos. No início do século XX, a situação pouco se tinha alterado, ao contrário do que acontecia em Espanha e Itália que, partindo de situações semelhantes, tinham já taxas de alfabetização à volta de $50 \%$. 
Nos anos 60 do século XX, o analfabetismo era da ordem dos $60 \%$ (e só os alfabetizados tinham direito de voto), valor que passou a $11 \%$ no início dos anos 90.

Quanto à população escolar, era da ordem de um quarto de milhão no início do século XX e é de cerca de dois milhões no final do século.

Actualmente, pode dizer-se que a escolaridade obrigatória de nove anos é universal, embora haja ainda fenómenos localizados de abandono (cerca de $2 \%$ ); quanto ao ensino secundário, ou seja, doze anos de escolaridade, temos taxas de conclusão da ordem dos $54,8 \%$ que é urgente aumentar.

O país viveu, assim, mais de um século de fraco investimento educativo, o que explica a situação específica que ainda hoje ocupa, tanto em relação aos países desenvolvidos do norte industrial e protestante, como em relação aos países latinos e católicos do sul da Europa.

Depois de 1974, desenvolveram-se políticas de democratização do acesso à educação e de prolongamento da escolaridade obrigatória, bem como acções de alfabetização e de educação de adultos; o país viveu a construção da democracia com múltiplas contradições, e as equipas que se sucederam no Ministério da Educação procuravam respostas imediatas para os numerosos problemas, sem projectos a longo prazo nem diinâmicas de mudança sustentadas. Cada governo, cada maioria, desenvolvia novas reformas e medidas centradas nas estruturas, nos conteúdos e nas modalidades de avaliação, na gestão das escolas, no acesso ao ensino superior.

Só em 1986 se elaborou e aprovou a primeira Lei de Bases do Sistema Educativo. Com efeito, em 1986 o Parlamento elaborou e aprovou, após um vasto debate público, a Lei de Bases do Sistema Educativo, que define as finalidades do sistema, os seus objectivos e a sua arquitectura.

Só então se tornou obrigatória a escolaridade obrigatória de nove anos. Este facto é revelador da situação educativa em Portugal, que chega aos anos 90 sem que a escolaridade obrigatória de nove anos seja uma realidade efectiva para todas as crianças e com fenómenos de 
insucesso e de abandono escolares muito elevados. O recenseamento da população de 2001 mostra que $32,6 \%$ da população empregada tem apenas quatro anos de escolaridade ou menos, 29,6\% têm nove anos de escolaridade, e apenas $22 \%$ frequentaram ou concluíram o ensino secundário. A tendência é para o aumento destas taxas de conclusão nos grupos etários mais jovens, mas o atraso não foi recuperado e Portugal está, no campo educativo, longe ainda dos seus parceiros europeus.

\subsection{A LEI DE BASES DO SISTEMA EDUCATIVO}

Esta Lei, aprovada em 1986 por (quase) unanimidade (com a abstenção de um único partido de centro-direita), tornou-se um texto de referência para a elaboração das políticas educativas. No entanto, dado tratar-se de um texto de orientação, embora muito extenso e detalhado, permitiu interpretações diversas o que levou a que, entre 1986 e 1995 se tenham sucedido novas reformas e medidas avulso de governo para governo (e até, num mesmo governo, segundo o ministro em funções), sem que tenha havido um esforço continuado para ultrapassar 0 «atraso educativo português».

As várias interpretações da Lei de Bases não permitiram estabilizar o sistema educativo quer no seu funcionamento (a abertura do ano escolar, por exemplo, variava de data de ano para ano e era sempre fonte de grandes confusões), quer nos seus resultados (o insucesso e abandono escolar era objecto de programas específicos, pontuais, e sem consequências duráveis na vida das escolas).

De facto, continuava a faltar um compromisso quanto a objectivos a atingir e a estratégias a desenvolver, para além das marcas distintas de cada governo.

\subsection{A SITUAÇÃO EM 1995}

Em 1995, as eleições deram a vitória ao partido socialista que formou um governo minoritário, sem maioria no Parlamento, num contexto que se pode caracterizar do seguinte modo:

- Uma crispação política no mundo da educação com todos os parceiros «de costas voltadas uns para os outros» e, sobretudo, para o Ministério da Educação. 
- Uma insatisfação social quanto ao estado da educação: o primeiro estudo nacional de literacia $^{2}$ revelava que quase $80 \%$ da população entre os 15 e os 65 anos se situava nos níveis mais baixos de competências de leitura, escrita e cálculo em situações da vida real. 0 impacto social deste estudo foi muito forte, confrontando o país com o seu atraso e com uma situação que urgia ultrapassar.

- Muitos problemas na escolaridade obrigatória de nove anos: insucesso e abandono elevados, uniformização da acção pedagógica, centralização da gestão educativa, ausência de políticas de inovação e de apoio às «boas práticas», ausência de uma política coerente de educação de adultos, fraca, muito fraca articulação entre educação e formação profissional.

- Falta de confiança na escola como bem público, como recurso individual e colectivo.

O governo, que tinha dado grande destaque à educação durante a campanha eleitoral e tinha organizado "Estados Gerais» em várias áreas, reunindo muitos protagonistas sociais, assumiu então a educação como uma prioridade e uma "paixão» ("a paixão pela educação», "com a razão e com o coração», foram os nossos slogans). Assumiu o compromisso de aumentar o PIB em $1 \%$ durante os 4 anos de mandato e elaborou uma estratégia para ultrapassar 0 atraso educativo português «no espaço de uma geração».

Era preciso que o país retomasse confiança e se mobilizasse para responder aos desafios educativos.

O Pacto educativo para o futuro foi um instrumento central nesta estratégia, que exigia a participação de todos os parceiros educativos e sociais e, portanto, a pacificação do mundo educativo, o diálogo e a definição de objectivos positivos, valorizando vontades e energias.

\footnotetext{
${ }^{2}$ Ana Benavente e outros (1996): A literacia em Portugal: resultados de uma pesquisa extensiva e monográfica. Lisboa, Fundação Calouste Gulbenkian / Conselho Nacional de Educação.
} 


\subsection{A CONSTRUÇÃO DA ESCOLA PÚBLICA EM PORTUGAL}

0 debate estratégico sobre o desenvolvimento educativo e a construção da qualidade exige uma clarificação teórica: há países em que a escolarização é o resultado de dinâmicas sociais e há outros (como em Portugal) em que a escolarização é imposta pelo Estado central, segundo várias modalidades, com objectivos de desenvolvimento económico e de coesão social. Isto significa que a obrigatoriedade formal precede as práticas sociais, e que a escola começa por ser uma retórica e uma obrigação imposta que é preciso levar à prática. Ou seja, a escolaridade obrigatória não é uma necessidade sentida pelas pessoas, pelas famílias, mas sim uma obrigação decidida e imposta pelo Estado.

Este voluntarismo estatal deu origem a grandes reformas que procuram responder aos problemas sociais, sem que haja dinâmicas sociais positivas que as suportem. Assim, os resultados das reformas ficam, sempre, muito aquém das expectativas o que, paradoxalmente, leva a novas reformas. A análise crítica destes processos defende 0 «fim das grandes reformas estatais» e a necessidade de criar mecanismos de regulação das instituições educativas, tendo em conta orientações comuns mas também a diversidade de situações (de cada comunidade, de cada território, de cada escola).

As «grandes reformas» ficam muitas vezes no papel, nos textos de lei e nas intenções dos governantes, e são interrompidas sem terem nem o tempo nem as condições necessárias para a sua plena concretização. Tal facto deve fazer-nos reflectir sobre as condições socio-políticas das mudanças educativas e sobre as próprias estratégias de mudança.

As sociedades e as escolas estão cansadas de grandes reformas, reagem muitas vezes contra as inovações decretadas pelos governos e torna-se difícil encontrar os caminhos para a construção educativa da escola para todos ${ }^{3}$.

No caso português, é preciso assinalar a centralização administrativa e a burocracia que levam a que as relações entre o Estado e os cidadãos sejam marcadas por "desconfianças» recíprocas. É uma herança de um passado autoritário que não respeitava os cidadãos nem

${ }^{3}$ D. Tyack e L. Cuban (1995): Tinkering Utopia. A Century of Public Reform, Cambridge, Harvard University Press. 
valorizava a participação social e que marca hoje ainda, de modo muito forte, a nossa vida colectiva. Estas dimensões das relações sociais pesam negativamente sobre os caminhos da construção da escola democrática. Sabemos ${ }^{4}$ que os processos de mudança educativa, difíceis e trabalhosos, exigem confiança, diálogo, participação de todos nas decisões, tempo, apoio e avaliação partilhada. A desconfiança entre parceiros educativos e as relações conflituosas com as autoridades criam bloqueios e dificuldades adicionais a processos que são, já, em si mesmos, problemáticos e muito exigentes.

\subsection{OS ACTORES DO «PACTO EDUCATIVO»}

O texto do Pacto foi elaborado no Ministério da Educação pela equipa política, e proposto aos diversos parceiros enquanto compromisso para a acção, no quadro da Lei de Bases da Educação e do programa do governo recém eleito.

O Pacto afirmava a educação como «um assunto de todos», de toda a sociedade e não apenas de professores, pais, alunos e funcionários.

Assim, definiram-se as bases gerais do pacto, os princípios gerais, os objectivos estratégicos e dez compromissos para a acção, definindo os principais parceiros para cada um desses compromissos. A identificação desses parceiros, numa "geometria variável», em função dos objectivos, de modo aberto e flexível, permitiu lançar o desafio para o debate em torno do «Pacto». Este conceito de geometria variável era importante, na medida em que cada objectivo implicava vários parceiros, mesmo se muitos deles são comuns às várias dimensões da acção social e educativa.

Em síntese, pode dizer-se que entre os parceiros estavam vários ministérios (e serviços públicos), associações, órgãos do poder local, direcções das escolas, sindicatos, organizações não governamentais, sociedades científicas e profissionais, fundações e individualidades do mundo cultural, científico e económico.

${ }^{4}$ Ver, por exemplo, o texto fundador de M. Huberman (1973): Comment s'opèrent les changements en éducation. Contribution à l'étude de l'innovation, París, UNESCO. 
Detalhando, temos, no caso português, os seguintes parceiros ${ }^{5}$ :

- Ministérios e secretarias de estado (da administração do território, da saúde, da justiça, da administração interna, da juventude e desportos, da solidariedade e segurança social, das finanças, da ciência e tecnologia, da cultura, do ambiente, do emprego e da economia.

- Associação nacional dos municípios e outros órgãos do poder local.

- Conselhos directos e conselhos pedagógicos das escolas.

- Confederação nacional das associações de pais, federações regionais e associações de pais das escolas.

- Associações de estudantes.

- Federações sindicais e sindicatos de professores.

- Centros de formação de professores de associações de escolas (estruturas de formação contínua de professores).

- Instituições privadas de solidariedade social, creches, instituições sociais de apoio à infância e à juventude, misericórdias e mutualidades.

- Associação do ensino particular e cooperativo.

- Fundações culturais e sociais.

- Associações culturais.

- Associações de defesa do património.

- Associações ecologistas.

- Confederações patronais.

- Confederações sindicais.

- Conselho de reitores das universidades portuguesas.

- Conselho de coordenação do ensino superior politécnico.

${ }^{5}$ Em Portugal, a educação e a formação profissional estão integradas em ministérios diferentes e têm diferentes estruturas de terreno. Existe um Conselho Económico e Social (governo, patrões e sindicatos), no quadro do qual se negociou um acordo de concertação estratégica, com uma forte componente educativa, ao mesmo tempo que decorria o processo do pacto educativo. 
Sublinhava-se a diversidade de parceiros na educação enquanto "assunto de todos» e procurava-se estabelecer compromissos institucionais e organizacionais, qualquer que fosse a natureza da instituição ou organização em causa, mas também compromissos informais e individuais em projectos, realizações e participações diversas.

O Pacto previa o desenvolvimento de negociações com vários parceiros (para a elaboração de medidas políticas bem como para a criação das necessárias condições de trabalho), o estabelecimento de protocolos específicos, o reforço do papel dos parceiros educativos, a criação de novos órgãos de participação local e a revalorização dos já existentes. Tudo isto se desenvolveria aos níveis local, regional e central, indo desde os amplos debates nacionais até à intervenção concreta em cada comunidade e em cada escola.

É preciso assinalar que Portugal já tinha, a nível nacional, um Conselho Nacional de Educação, cujo presidente é eleito pelo Parlamento e onde estão representados todos os parceiros sociais e educativos (partidos políticos, individualidades, pais, estudantes, escolas, universidades, sindicatos, associações científicas e profissionais). Este Conselho acompanha as políticas educativas, elabora pareceres e recomendações e organiza debates e seminários que publica de modo regular.

No quadro do processo de descentralização da gestão da educação, criou-se uma nova estrutura: o conselho local de educação, mais tarde designado conselho municipal de educação. Procurava-se que, em cada território, se articulassem as políticas educativas e se apoiassem realmente as escolas. Para isso, os professores e os representantes das escolas, o poder local, os pais, os serviços públicos, as associações culturais, sociais e económicas, as colectividades, as forças de segurança e outras instâncias localmente relevantes pertenciam a este conselho, cujas funções eram as de apoiar a vida educativa local, melhorando as escolas e enriquecendo a educação dos jovens, alargando o espaço educativo e articulando actividades.

Voltando ao Pacto educativo, não se tratava, evidentemente, de "assinar um texto» com os parceiros, mas de construir acordos capazes de assegurar alguma continuidade e suporte às políticas educativas, mobilizando a sociedade civil em torno da educação. 
Assim, organizou-se uma «ronda» de contactos, encontros e reuniões através do país, sempre com a presença de um membro da equipa política; realizou-se um dia «D» (de debate) em todas as escolas de todos os graus de ensino, em torno dos problemas educativos e suas soluções; seguidamente, o Pacto foi apresentado no Parlamento para debate com todos os partidos políticos. Foi um momento simbólico muito importante, revelador das lógicas do mundo político em relação à educação, como veremos nos pontos seguintes.

\section{O PACTO EDUCATIVO PARA O FUTURO: UM EXERCíCIO DE DEMOCRACIA}

\subsection{A EDUCAÇÃO, «ASSUNTO DE TODOS»}

Numa situação nacional caracterizada por baixos níveis de educação e de formação da população e por fracos indicadores de qualidade (elevado insucesso escolar e abandono, más classificações nos estudos comparativos internacionais sobre resultados dos alunos), era absolutamente imperioso levar a sério o "atraso educativo português", expressão presente em todos as análises e discursos políticos, sociais, culturais e económicos.

Em 1995, a situação educativa estava muito crispada. com negociações falhadas e com sucessivas manifestações de professores e de estudantes e «quedas» de ministros da educação.

Tendo a escolaridade obrigatória sido imposta pelo Estado (ao contrário dos países em que a procura vem da sociedade civil) no final dos anos 60, e, sobretudo, após 1974, as comunidades continuavam a não sentir a escola como um bem e como um recurso, mas antes como uma «obrigação» (com fenómenos de trabalho infantil e de «fuga» à escola), era preciso envolver toda a sociedade num esforço educativo, definindo estratégias de mudança graduais, negociadas e participadas.

"O Pacto educativo é um pacto, um acordo - tácito, escrito ou estratégico - não sobre o que nos une ou nos separa mas sobre o que é realmente urgente fazer nos domínios que nos importam a todos», afirma o Ministro da Educação em 1996, sublinhando a necessária pacificação 
e normalização das relações institucionais entre o Ministério da Educação e todos os parceiros educativos ${ }^{6}$.

Nesta intervenção no Parlamento, o ministro acrescenta: «0 grande objectivo deste debate parlamentar é o de lançar as bases para um acordo e um entendimento que permitam o progresso do país num domínio estratégico e decisivo para o nosso futuro; neste "coração da democracia», o Parlamento, tomamos uma iniciativa de reflexão e de acção que assume a educação como uma ambição de toda a sociedade portuguesa; [...] trata-se de definir orientações de ordem geral que tenham repercussões para além do fim de cada mandato governamental. É preciso criar condições de estabilidade que evitem as incertezas e hipotequem o futuro dos jovens [...] As relações entre o Estado, a sociedade e a educação devem ser redefinidas de modo a assegurar uma maior participação e representatividade. A democratização não se alcança apenas através da massificação escolar. A sociedade actual vive uma situação de dilema entre democracia e qualidade, entre igualdade e diferença, entre massificação e singularidade. Por isso, a gestão estratégica da qualidade educativa implica o desenvolvimento de processos de informação e de comunicação, uma maior visibilidade positiva e mobilizadora do sistema e a melhoria da imagem do ensino, em nome da credibilidade da educação e da escola» ${ }^{7}$.

\subsection{O PACTO EDUCATIVO PARA O FUTURO, UM PACTO SOCIAL}

Os principais objectivos do Pacto eram os seguintes:

- Lançar o desafio para um amplo debate público sobre os problemas da educação e as suas soluções, identificando prioridades e acções concretas.

- Alargar o conceito de parceiro educativo, identificando um vasto conjunto de interlocutores sociais, o que não deixou de criar resistências junto dos parceiros «tradicionais» (nomeadamente junto das estruturas sindicais de professores).

\footnotetext{
${ }^{6}$ E. Marçal Grilo, in prefácio a A. Teodoro (coord.) (1996): Pacto Educativo, aspirações e controvérsias, Lisboa, Texto Editora.

7 In Diário da Assembleia da República, 20/6/1996, I série, núm. 83, VII Legislatura.
} 
- Elaborar os consensos possíveis para a condução das políticas e para a consolidação das respostas concretas «consenso não significa unanimidade e ainda menos conformismo; trata-se de um consenso construído sobre as convergências possíveis a partir de diferentes posições, interesses e pontos de vista [...], em termos de "geometria variável", ou seja, através de partenariados assentes em vantagens recíprocas em domínios concretos, sem que nos enganemos quanto à possibilidade de acordos imaginários sobre todas as maténias»> ${ }^{8}$.

- Criar condições para uma certa estabilidade da vida educativa e para a continuidade de processos estruturantes.

- Valorizar o enquadramento institucional das transformações e da acção educativa concreta, de modo a que a mudança se baseie na transformação sustentada e sustentável das organizações e das práticas.

- Promover mudanças nas atitudes e nas práticas sociais no sentido da concertação, da co-responsabilidade e da consolidação dos resultados obtidos.

- Desenvolver estratégias de mudança graduais que privilegiam os mecanismos de acompanhamento, de avaliação e de correcção; o tempo das grandes reformas centralizadas está ultrapassado, e a mudança tem que ter em conta a diversidade de situações e exige o envolvimento de todos os parceiros educativos.

Estes objectivos, aqui sintetizados, representavam uma verdadeira revolução no modo de encarar a educação e a participação social num país que tradicionalmente deixava a educação nas mãos do Estado e que vivia com amargura e desencanto 0 "atraso educativo português».

${ }^{8}$ A. Santos Silva, ex-secretário de Estado da Administração Educativa, in A. Teodoro, op. cit., pp. 53-59. 


\subsection{O PACTO EDUCATIVO, UM PROCESSO NO TEMPO}

Este processo de «apelo e convite» à participação iniciou-se em Outubro de 1995, com a entrada em funções do novo governo.

O texto do Pacto foi divulgado em 1996, e o debate no Parlamento teve lugar em Junho de 1996.

O debate público, assim como as campanhas de informação, as negociações e a celebração de protocolos e acordos vários prosseguiu até ao fim do primeiro mandato do governo, com a mesma equipa política, em 1999. Os objectivos do Pacto foram retomados, durante e após esse período, em textos oficiais de orientação e em documentos de enquadramento dos ensinos básico, secundário e superior ${ }^{9}$.

O segundo mandato do partido socialista durou de 2000 a 2002 [(foi interrompido a meio do mandato por eleições antecipadas, dado o primeiro ministro se ter demitido após a derrota do PS nas eleições autárquicas (locais)], e manteve as orientações e os objectivos estabelecidos no Pacto.

A vitória eleitoral de uma coligação de centro-direita e de direita (partido social-democrata e partido popular) em 2002, e a chegada ao governo de uma nova maioria alteraram profundamente a situação. Desvalorizando o diálogo e a concertação, o actual governo (em 2004) suspendeu vários processos de mudança e apresentou no Parlamento uma nova Lei de Bases da Educação, que se prepara para aprovar com os votos contrários de toda a oposição.

Enquanto em 1986 se aprovou a primeira Lei de Bases do Sistema Educativo, documento fundador e de referência, com um vasto consenso político no Parlamento, temos agora, a meio de um mandato, uma Lei de Bases da Educação que será aprovada por uma maioria (118 deputados em 230) conjuntural.

Banaliza-se uma Lei de enquadramento (que não obriga a uma aprovação por $2 / 3$ dos deputados) e, pela primeira vez na democracia

9 O Ministério da Educação elaborou, durante o mandato 1995-99, três documentos de orientação: Autonomia e qualidade (ensino superior); Educação, integração e cidadania (ensino básico); Desenvolver, consolidar, orientar (ensino secundário), explicitando políticas e metas para cada um destes sectores. 
portuguesa, uma Lei de Bases nascerá e morrerá com a maioria que a aprovou. Esta situação está bem longe do que se pretendia com o Pacto educativo, e a educação voltou a ser apenas mais uma área de governo, precária e conflituosa (assinale-se que várias federações de sindicatos de professores, bem como a confederação de associações de pais e outros parceiros, anunciaram já a sua oposição a esta Lei de Bases).

Quanto ao Pacto educativo, enquanto processo temporal, é difícil avaliar os seus efeitos, pois a prioridade educativa tornou-se dominante em várias instâncias e os processos de tomada de consciência e de participação são permanentes em democracia.

É importante também assinalar que o presidente da República, Jorge Sampaio, socialista (eleito em 1996 e em funções, num segundo mandato, até 2006), tem sido uma «instituição» permanentemente preocupada e activa quanto à necessária mobilização da sociedade portuguesa na resolução dos problemas educativos do país.

\subsection{O PACTO EDUCATIVO PARA O FUTURO, UM TEXTO DE REFERÊNCIA}

O Pacto pretendia ser uma «mapa» de navegação para acordos duradouros, mobilizador e aberto, assegurando, ao mesmo tempo, a continuidade das orientações fundamentais e a inovação, a criatividade bem como o espaço de negociação e de decisão dos parceiros educativos. Tratava-se de definir uma plataforma aberta que permitia a congregação de esforços, de energias e de boas vontades dos actores sociais, dos agentes económicos e dos criadores culturais. Não se pretendia que houvesse assinaturas formais ou que se estabelecessem contratos jurídicos. Tratava-se, de facto, de um "contrato social» capaz de valorizar o papel da educação na sociedade portuguesa e de enriquecer a participação na construção da qualidade.

0 texto do Pacto (ver o texto integral no anexo) estava estruturado em quatro capítulos: as bases gerais do acordo, os princípios de orientação, os objectivos estratégicos e os 10 compromissos para a acção.

- As bases gerais do acordo centravam-se na prioridade política da educação, definindo-a como uma questão pública e uma ambição nacional, e formulando diversas exigências quanto às políticas; estas deviam orientar-se por princípios explícitos, definir estratégias e assumir prioridades de acção, 
de modo a permitir a sua concretização por fases, graduais, apoiadas, avaliadas e corrigidas.

- Os princípios de orientação explicitavam as opções de fundo em torno da educação como «assunto de todos», alargando o conceito de parceiro educativo; sublinhavam a importância da equidade na construção da qualidade, e definiam a escola como o lugar nuclear do processo educativo, o que implicava a sua inserção social em redes e exigia a sua diversidade organizacional; afirmavam a necessidade da participação e responsabilidade de todos na vida educativa, redefinindo as relações entre Estado, educação e sociedade civil; chamavam a atenção para a necessária credibilidade pública das escolas através da qualidade do seu trabalho, pois sem confiança não há sucesso; referiam a educação e a formação dos cidadãos ao longo da vida como uma condição necessária para o desenvolvimento económico e social, chamando a atenção para a educação de adultos; insistiam na importância da visibilidade social dos processos educativos e dos seus avanços, o que exigia a criação de sistemas de comunicação e de informação adequados.

- Os objectivos estratégicos retomavam e concretizavam os princípios de orientação, propondo a criação de estruturas formais de participação na gestão do sistema e das escolas, e o desenvolvimento de mecanismos de apoio aos pais e às suas associações: apostava-se na modernização e descentralização do sistema educativo, assegurando um equilíbrio dinâmico entre as funções centrais de concepção, de arbitragem, de regulação e de identificação e correcção das assimetrias, e o desenvolvimento de projectos adequados em cada território educativo; apoiava-se a autonomia das escolas e a valorização do seu trabalho e da sua imagem pública; promovia-se a educação ao longo da vida, assegurando a multiculturalidade, a articulação entre educação formal e não formal, entre educação e formação, e reforçando a formação cívica e cultural da população; a educação pré-escolar era afirmada como uma prioridade enquanto primeira etapa da educação de base de qualidade para todos, defendendo o sucesso das aprendizagens através de pedagogias diferenciadas; redefinia-se 0 papel do ensino secundário, diversificando as vias de formação tecnológicas 
e profissionais, reforçando o seu valor formativo e a sua identidade; aumentava-se a oferta pública de ensino superior num desenvolvimento equilibrado com qualidade e rigor e revisão dos modos de financiamento; insistia-se na valorização e na responsabilidade (e avaliação) dos profissionais da educação, assumindo a melhoria do seu estatuto e das suas condições de trabalho.

- Finalmente, quanto aos 10 compromissos de acção, trata-se da concretização dos objectivos estratégicos, identificando os principais parceiros e definindo as acções prioritárias (ver texto integral do Pacto no anexo).

Os 10 compromissos eram os seguintes: transferir competências para os órgãos do poder local, no quadro da descentralização educativa; centrar as políticas educativas nas escolas; criar um sistema nacional de educação pré-escolar; melhorar a qualidade da educação; assegurar a educação e formação ao longo da vida; reforçar a ligação entre educação e formação profissional; valorizar os educadores e os professores; rever os sistemas de financiamento da educação; promover o desenvolvimento equilibrado do ensino superior, e valorizar o papel do ensino privado e cooperativo.

Definiam-se acções específicas para cada um destes 10 compromissos, assim como modalidades e prazos para a sua concretização. Não se tratava de definir os detalhes de cada intervenção mas sim de traçar a sua arquitectura e de fixar metas.

\subsection{O PACTO EDUCATIVO PARA O FUTURO: ACORDOS, DIFICULDADES, CRÍTICAS E EQUIVIOCOS}

Os acordos

A primeira fase de debate sobre o Pacto teve lugar nas escolas; foram convidados os parceiros educativos e suspenderam-se as actividades lectivas num dia simbólico (dia D) para que todos pudessem participar.

A equipa ministerial percorreu o país, como já foi referido, animando as reuniões, assegurando a informação e assumindo compromissos junto das escolas, das autoridades locais e da imprensa, radio e TV. 
Esta «campanha» teve o seu momento nacional mais forte com a apresentação do Pacto no Parlamento.

A grande maioria dos parceiros manifestava o seu acordo quanto à estratégia adoptada, e mostrava-se favorável às grandes linhas de orientação política apresentadas no Pacto e cujas primeiras medidas se concretizavam já no terreno.

Veremos mais adiante neste texto quais foram os resultados positivos, imediatos e a médio prazo, deste processo.

É importante recordar que, neste primeiro ano de mandato, 1995-96, o objectivo principal era o de pacificar a vida educativa, criando condições de confiança favoráveis à mudança das escolas e à construção participada da qualidade.

\section{As dificuldades}

A primeira dificuldade que encontrámos foi uma tripla desconfiança: desconfiança em relação ao Ministério da Educação (cuja acção era criticada há muito tempo e cuja imagem estava muito desvalorizada), desconfiança em relação ao texto em si mesmo (mais palavras??), e desconfiança em relação à própria ideia de "pacto». Havia um certo receio quanto a eventuais perdas de espaço crítico de uns e de outros (se concordamos, não nos estamos a auto-limitar??).

Aliás, não fazia parte das nossas (recentes) tradições democráticas a ideia de acordos de natureza estratégica; cada força política era muito «zelosa» das suas posições, sobretudo num campo marcadamente ideológico como é o da educação.

Nas escolas, a maior dificuldade era a preocupação imediata com (pequenos/grandes) problemas concretos e urgentes. Os professores, as autoridades locais e os pais eram sensíveis aos princípios e aos objectivos do Pacto, estavam disponíveis para debater e para negociar soluções, mas sentiam a urgência de respostas imediatas; estas eram, em geral, numerosas e impossíveis de satisfazer todas ao mesmo tempo e com a rapidez desejada. Todos queriam «tudo e já». Esta fórmula um pouco crua resume a pressão e as imensas expectativas face ao governo, sem que os parceiros locais se envolvessem na procura de soluções. 
A «ronda» através das escolas também confirmou a diversidade de situações: havia escolas disponíveis para a mudança e havia outras muito bloqueadas na acção. Confirmou também a importância dos professores (das pessoas) na vida educativa: não era nos melhores edifícios, que dispunham de condições materiais e sociais mais favoráveis, que havia mais determinação para a qualidade (às vezes, bem pelo contrário).

\section{As críticas}

As críticas vieram de vários sectores.

Os sindicatos de professores, por exemplo, não ficaram nada entusiasmados com a "entrada em cena» de novos parceiros educativos. Consideravam que os parceiros «directos» perdiam importância e criticaram o facto de só o Ministério da Educação aparecer referido em todas as acções prioritárias previstas no Pacto. Pretendiam que o Pacto ignorava o papel central das organizações sindicais, dos alunos e dos pais.

Outra crítica centrava-se no carácter vago e impreciso ( «metafísico») do texto do Pacto. Uma federação sindical afirmava que o Ministério, além de desvalorizar os sindicatos, apresentava uns enunciados difusos que permitiriam legitimar toda a espécie de medidas «avulso», o que não contribuiria em nada para melhorar a educação.

Durante o debate parlamentar, as críticas de direita e de esquerda ignoram o Pacto e centram-se na realidade imediata, desde os exames nacionais ao conteúdo de certos programas.

Critica-se o apelo ao diálogo e exigem-se decisões imediatas e concretas, considerando que o Pacto é uma mão cheia de nada (a direita) e que é preciso um pacto para o presente e não para o futuro (a esquerda).

As críticas podem ser sintetizadas em cinco tipos ${ }^{10}$ :

- Trata-se de um pacto «à la carte», um «pick and choose» que não reforça os compromissos sociais.

${ }^{10}$ Críticas assumidas pelo Partido Social Democrata, então o maior partido da oposição, in Diário da Assembleia da República, op. cit. 
- O Pacto não traz nada de novo em relação a outros textos de referência, tais como a Constituição ou a Lei de Bases do Sistema Educativo,

- O Pacto não propõe soluções concretas e procura acordos inúteis em torno de princípios que são como a «água pura: transparente, insípida e inodora»,

- Trata-se de um «alibi» para ganhar tempo, para evitar as decisões, uma verdadeira "cortina de fumo»,

- O Pacto não garante a estabilidade, mas é uma espécie de guarda-chuva que permite consensos que já estão consagrados noutros textos de referência.

O Pacto é, portanto, inútil.

Alargando esta síntese ao debate nacional, encontramos de novo cinco ordens de argumentos:

- A oposição à própria ideia de pacto, pois é o mercado que deve regular a oferta e a procura em educação.

- A afirmação de um pragmatismo absoluto, que considera dispensável qualquer debate em torno de princípios e de objectivos e que exige soluções técnicas imediatas, "eficientes»e «eficazes».

- A inutilidade do Pacto, face à existência de outros textos nacionais de referência.

- A descrença numa visão ética da política e a convicção de que só são possíveis acordos pontuais e concretos, dados os interesses divergentes e até opostos dos parceiros educativos.

- O cepticism o face aos políticos e aos seus com prom issos ${ }^{11}$.

\section{Os equívocos}

Houve múltiplos equívocos sobre o Pacto, equívocos que estão presentes, aliás, nas críticas formuladas.

11 João Barroso, professor universitário, sintetizou as críticas feitas ao Pacto educativo num texto intitulado "Do pacto educativo à educação como pacto», in A. Teodoro, op. cit., pp. 79-89. 
Seria um acordo sobre princípios e valores ou um contrato sobre medidas concretas? O governo apostava na primeira hipótese, os partidos da oposição e os sindicatos, por exemplo, apostavam na segunda. Esta contradição atravessou todos os debates: qual era a natureza do texto proposto? Pacto ou contrato?

Um outro equívoco tinha a ver com o «registo» do Pacto: tratavase de definir um destino (um fim) ou um caminho para esse destino? Para o governo, tratava-se de obter acordos quanto ao destino a atingir. Para outros parceiros, a prioridade estava nos caminhos a seguir de imediato.

Qual era o «núcleo duro» do Pacto? As opções políticas ou as soluções técnicas? O governo centrava-se nas opções políticas, a oposição questionava as soluções técnicas.

O exercício que consistia em partir de princípios para chegar às acções, não clarificou o debate mas, pelo contrário, alimentou os equívocos.

Os equívocos manifestaram-se tanto ao nível conceptual (natureza do Pacto) como ao nível operacional (texto prospectivo ou programa de acção?).

Tratava-se de uma daquelas situações paradoxais que os governantes bem conhecem: se as propostas se centram nos princípios, são consideradas vagas e inúteis, se as propostas se centram nas acções, os acordos tornam-se parcelares e dependentes dos resultados a obter.

\section{O PACTO EDUCATIVO PARA O FUTURO: BALANÇO DE UM PROCESSO}

\subsection{OS RESULTADOS OBTIDOS}

Não é fácil avaliar a curto prazo os resultados de um processo social. No entanto, podemos destacar alguns indicadores significativos:

- Durante os debates sobre o Pacto, identificamos mais de mil textos, artigos e intervenções públicas, individuais e colectivas, sobre 0 assunto. 
- Tornou-se visível um maior destaque da comunicação social em relação aos temas educativos; hoje, quase todos os jornais diários têm uma "página de educação», produzindo mesmo dossiers para professores e alunos, e há debates regulares na rádio e na TV.

- Celebraram-se numerosos protocolos com os parceiros educativos: com a confederação de associações de pais, assegurando uma maior participação nas escolas e tempo laboral disponível para essa participação; com a associação de municípios, regulando transferências de competências (edifícios, transportes, acção social, etc.); com os sindicatos de professores (sobre o estatuto docente, a carreira, as condições de trabalho, etc.); com a associação do ensino particular e cooperativo; com associações científicas para apoio às escolas; com instituições de ensino superior para acompanhamento de projectos de inovação; com vários ministérios, articulando áreas de educação e formação, enriquecendo as novas tecnologias, intensificando os trabalhos sobre saúde, ambiente, etc.

- Criaram-se novas estruturas de participação (conselhos locais de educação, por exemplo) e dinamizaram-se as já existentes.

- Desenvolveram-se processos participados relativos à autonomia das escolas, à reorganização do ensino básico e do ensino secundário que fundamentaram a elaboração e aprovação de textos legais.

- Animaram-se foruns na Internet, com milhares de participantes, à volta de vários domínios da política educativa,

- Retomaram-se estratégias de inovação "em bola de neve», valorizando e apoiando as boas práticas, enraizadas na realidade das escolas, graduais e reguladas pela experiência.

As acções previstas no Pacto prosseguiram durante todo o mandato de 1995-99, e os resultados obtidos fazem parte do balanço da actividade do governo.

Um exemplo que traduz os efeitos das estratégias de participação é o seguinte: em 1988, os professores e os seus sindicatos opunham-se absolutamente à entrada dos pais e doutros parceiros nas 
estruturas escolares. Em 1998, por comum acordo, a assembleia de escola, órgão que aprova o projecto educativo, o regulamento interno e 0 plano de actividades, passa a ser constituída por $50 \%$ de professores e $50 \%$ de outros parceiros, entre os quais os pais. Mas foi preciso garantir que o presidente seria, sempre, um professor eleito pela assembleia.

As «marcas» deste período que fez da educação «uma prioridade e uma ambição» só poderão ser avaliadas a médio e a longo prazo.

\subsection{AS LIÇÕES APRENDIDAS}

A lições aprendidas foram múltiplas e severas. A primeira lição tem a ver com a importância da informação e da comunicação.

Houve ingenuidade e também dificuldades objectivas que nos levaram a organizar a informação de modo selectivo, conduzindo, por exemplo, os debates em escolas-pólo que reuniam várias escolas de uma mesma zona. Brochuras e folhetos divulgados em jornais nacionais apoiavam estes debates que reuniam os vários parceiros educativos. Mas diziam-nos, constantemente, que «não havia informação» e que muitos (pais, professores, autarcas, etc.) se mantinham à margem deste processo. Falta de informação ou alibi para não se implicarem??

Também tivemos muita dificuldade nos canais para assegurar a informação às escolas. Apesar de contactarmos com todas as escolas, a circulação da informação revelou-se difícil; ou os documentos ficavam na direcção, ou eram postos em placards que ninguém lia, ou os professores que participavam nos debates não comunicavam com os colegas.

Outro fenómeno preocupante foi o da desinformação; havia múltiplas interpretações, por vezes divergentes e até perversas, em relação às nossas propostas; criavam-se equívocos difíceis de esclarecer, ou porque se generalizava uma informação parcial, ou porque se imaginava tudo o que podia correr mal em cada proposta, ou porque havia, constantemente, «rumores» e «boatos» que dificultavam a informação adequada. Trata-se de fenómenos sociais de leitura e de interpretação da informação que tivemos dificuldade em gerir e que exigem muito tempo, no sentido da duração e continuidade dos processos. 
Uma segunda lição deste processo tem a ver com o poder das estruturas regionais e locais dos ministérios e dos serviços oficiais; as mediações entre o nível central e o local «resistem» à mudança e agarram-se aos seus pequenos poderes. Tudo o que dizia respeito à autonomia das escolas ou à conquista de espaços de liberdade e de flexibilidade ao nível local, suscitava passividades, silêncios e resistências mais ou menos «escondidas» dos directores dos serviços, que tinham as suas próprias interpretações das orientações do governo. Não se tratava forçosamente de falta de lealdade ou de uma vontade deliberada de «sabotar», mas sim de pontos de vista «auto-centrados» e muito enraizados em rotinas.

Uma terceira lição da experiência relaciona-se com a existência de diferentes lógicas e culturas no interior dos serviços oficiais. Havia orientações comuns mas tudo dependia, afinal, da boa vontade das pessoas, porque as orientações não correspondiam aos «hábitos» e ao «que sempre se fez». Os próprios serviços constituíam obstáculos inesperados. Revelava-se toda a "espessura» organizacional que a psicosociologia das organizações tão bem analisa...

Uma quarta lição diz respeito à pressão para a uniformidade que se sente em muitos níveis de acção e por várias razões. A primeira razão é a tradição centralista do país. Outra razão é a confusão ideológica entre igualdade e equidade. Uma escola da «igualdade» desconfia da diversidade e prefere a igualdade formal (que, como mostrou há muito Pierre Bourdieu, produz novas desigualdades). Os sindicatos de professores foram os campeões da defesa de «o mesmo para todos em todas as escolas».

Uma quinta lição que aprendemos confirma a força conservadora dos sindicatos de professores em domínios inesperados. Os interesses imediatos dos professores, um certo «comodismo» e um espírito de corpo muito enraizado, levaram à sua oposição a medidas que acreditávamos serem consensuais na luta contra o abandono e o insucesso escolar.

Uma sexta lição centra-se nas exigências políticas para que um processo de participação tenha êxito. Teria sido preciso muito mais tempo e continuidade no governo. 0 partido socialista teve uma só equipa durante o primeiro mandato, mas teve três equipas diferentes durante os dois anos seguintes (2000 a 2002); quando os ministros e secretários de estado se sucedem... perde-se força e coerência. Houve processos 
interrompidos e perdeu-se energia, embora formalmente se mantivesse o mesmo programa de governo.

A sétima lição tem a ver com a diversidade de interesses dos protagonistas; sabemos que estes interesses são muitas vezes divergentes e que, mesmo no interior de cada sector (os pais, por exemplo) nem todos querem as mesmas coisas nem têm as mesmas expectativas e as mesmas exigências. Esta realidade torna os processos de negociação muito pesados; sentimo-nos, por vezes, prisioneiros destes processos que atrasavam as decisões. Mas como transformar a realidade sem a participação efectiva daqueles que a constroem?

Sublinhando o «melhor» e o "pior» desta experiência, considero o melhor a criação de um sistema nacional de educação pré-escolar através de partenariados entre os sectores público, privado e social. Quanto ao pior, foram as fraudes cometidas por alunos e pais de classes médias, explorando no seu interesse próprio a flexibilidade das normas e os espaços de liberdade; a apresentação de centenas de atestados médicos para a dispensa de provas para facilitar o acesso ao ensino superior, em certas escolas, criou "casos» que levaram à revisão da lei no sentido da sua uniformidade e rigidez.

\subsection{QUAL A PERTINÊNCIA DESTA EXPERIÊNCIA NOUTROS CONTEXTOS?}

Nas dinâmicas sociais, não se pode transferir um processo de um contexto para outro, como é evidente. As situações são diferentes, as lógicas de acção são marcadas pela história, pelas tradições e pela cultura, as fases de desenvolvimento educativo não se podem sobrepor. Além de tudo isto, as realidades são construídas e reconstruídas pelos actores nos seus contextos, mediatizadas por valores, por experiências e por representações sociais que as tornam singulares. Mas, para além das singularidades também há regularidades nas dinâmicas sociais, educativas e institucionais.

Com efeito, pode-se aprender com a experiência alheia, podese pensar a nossa realidade por referência (e contraponto) à dos outros, podemos integrar sugestões e propostas que enriquecem a nossa prática. A reflexão sobre realidades diferentes da nossa assegura uma «descentração» que pode clarificar a nossa própria realidade. 
No caso preciso do Pacto, há um valor heurístico quanto aos princípios, aos objectivos, aos conteúdos, às acções e às estratégias.

Qual a prioridade atribuída à educação? Que articulação entre educação e formação profissional? Que políticas sociais são necessárias para o sucesso das políticas educativas? Qual o papel do Estado central? Que relações estabelecer entre os vários níveis de poder? Quais são os principais problemas educativos do país? Quais as medidas mais urgentes? Que estratégias para o seu sucesso? Que diversidades sociais e territoriais é preciso ter em conta? Qual o papel dos parceiros educativos? Há que criar novas estruturas de participação? Quais os obstáculos previstos? De que natureza? Como poderemos atenuá-los e ultrapassálos? Que dinâmicas é preciso criar entre as mudanças materiais e as mudanças pedagógicas em educação? Que mecanismos de apoio e de avaliação é preciso assegurar?

Muitas outras perguntas se podem formular projectando o contexto de cada país (as singularidades) nas questões comuns às dinâmicas sociais e educativas (as regularidades), num exercício de descentração fértil e lúcido.

\subsection{A APRECIAÇÃO GERAL DA EXPERIÊNCIA}

Uma apreciação geral, alguns anos depois, permite sublinhar os pontos seguintes, que são ao mesmo tempo certezas, dúvidas, perplexidades e esperança para o futuro:

- É muito difícil, do ponto de vista político, atribuir a «prioridade à educação»; primeiro, porque esta afirmação aumenta as expectativas quanto à resolução imediata de todos os problemas, o que é impossível; depois, há interesses muito diferentes e, por mais consenso que se procure, há sempre descontentes; finalmente, porque a educação tem «tempos» que não correspondem aos «tempos» políticos. Um governo é eleito por quatro anos e é sempre mais sedutor tomar medidas visíveis do que medidas exigentes, cujos resultados positivos só se revelarão muitos anos depois. Daqui decorre a importância de pactos que assegurem o tempo necessário às mudanças educativas, para além dos tempos políticos. 
- Quando a educação se torna mais visível, torna-se visível para o pior e para o melhor; os media, na sua lógica própria, preferem as novidades e os incidentes, não se interessam pelo que é discreto e modesto mas portador de mudança. Contribuem para criar representações sociais por vezes distorcidas em relação à realidade concreta.

- O processo social em torno do Pacto educativo para o futuro mudou a realidade; mesmo se as críticas foram numerosas e o Pacto foi en si mesmo rejeitado, aumentou o debate público sobre a educação, criaram-se órgãos de participação, aumentaram as expectativas e as exigências sociais face à escola.

- Reforçou-se a afirmação da escola pública, capaz de evoluir, de aprender, de mudar, de construir a qualidade; esta experiência torna-se ainda mais preciosa num momento em que se vive em Portugal um reforço do statu quo com a tentativa de retorno a modelos da escola tradicional. "Atrás de tempos, tempos vêem», diz-se em português; será preciso, quando as condições políticas o permitirem, retomar esta experiência de modo "revisto e corrigido».

Pode dizer-se que o Pacto foi educativo em si próprio, pois contribuiu para a cidadania activa. Mas é a educação que deve assumir o estatuto de um pacto permanente, actualizado e assumido em todos os momentos e em todas as dimensões da vida educativa.

É verdade que o Pacto não evitou rupturas e descontinuidades, mas surgiu como uma nova possibilidade de acção social e política, mais rica e mais inteligente.

O Pacto educativo retomará a sua função estratégica num futuro que esperamos com esperança e com ambição. 


\section{ANEXO}

\section{TeXto Integral do PACTO EDUCATIVO PARA 0 FUtURO}

\section{BASES GERAIS DO ACORDO}

Os parceiros do PACTO EDUCATIVO PARA O FUTURO aceitam que:

1.1 A educação e a formação configuram áreas de prioridade política em Portugal. Da sua qualidade depende em parte significativa a sustentabilidade do desenvolvimento do País. A melhoria do nosso sistema de formação não é uma condição suficiente, mas é uma condição indispensável e altamente favorável para o nosso desenvolvimento social.

1.2 A educação é uma questão pública e uma ambição nacional. As grandes opções e linhas de orientação estratégica da política educativa podem e devem ser objecto de negociação e acordo entre os protagonistas do processo educativo: autoridades, pais, professores, outros técnicos de educação, estudantes. Este acordo é necessário para garantir a mudança de atitude social face às questões educativas, para a concertação e co-responsabilização de vários parceiros numa missão que é nacional, e para a continuidade das políticas.

1.3 A política educativa deve ser orientada por princípios, deve identificar objectivos estratégicos e deve definir áreas prioritárias de intervenção. As acções e iniciativas que asseguram a operacionalização de uma política devem enquadrarse nos princípios e objectivos definidos e devem ser desenvolvidas de forma faseada, gradual e programada, pressupondo a existência de mecanismos de acompanhamento, avaliação e correcção. 


\section{PRINCÍPIOS GERAIS DO PACTO}

O PACTO EDUCATIVO PARA O FUTURO será orientado pelos seguintes princípios gerais:

2.1 A educação é um assunto de todos. Não interessa apenas aos professores e aos estudantes, aos pais, aos técnicos e aos decisores políticos. Interessa a todos os Portugueses. As suas instituições, organizações e representantes devem ser chamados a intervir activamente na definição, realização e avaliação da política educativa. E não necessariamente apenas através do diálogo de cada um com o Estado, mas também, e cada vez mais, no diálogo dos parceiros entre si, estimulado e arbitrado pelo Estado.

2.2 A finalidade essencial do processo educativo é o desenvolvimento e a formação global de todos, em condições de igualdade de oportunidades, no respeito pela diferença e autonomia de cada um. A formação global é pessoal, cívica, científica, cultural, técnica e prática. A intervenção do Estado deve pautar-se pela promoção das condições para o desenvolvimento do processo educativo, pela concretização dos princípios da equidade e da igualdade de oportunidades, pela atenção particular às pessoas e grupos mais desfavorecidos em recursos materiais e culturais, pela correcção das assimetrias sociais e regionais mais gravosas.

2.3 A escola é um lugar nuclear do processo educativo. A escola é, hoje, uma realidade multiforme, admitindo várias soluções organizativas, devendo assumir-se cada vez mais como um elo de sistemas e comunidades locais de formação.

2.4 As relações entre o Estado, a educação e a sociedade devem ser redefinidas, por forma a que seja possível assegurar uma maior participação das diversas forças e parceiros sociais nas decisões e na execução das políticas educativas, em todos os níveis de administração, e desenvolver processos de coresponsabilização social no funcionamento do sistema educativo.

2.5 A democratização da educação não se alcança apenas pela massificação da frequência dos vários níveis de escolaridade. 0 processo de democratização do acesso à educação deve 
ser desenvolvido, articulando a universalização da escolaridade básica com uma acrescida difusão dos níveis secundário e superior, garantindo, simultaneamente, o rigor e a qualidade do ensino e das aprendizagens, enquanto condições necessárias para o renovar da confiança social na escola e na educação.

2.6 A educação e a formação global dos cidadãos ao longo de toda a vida constituem uma condição necessária para o desenvolvimento económico e social, o que implica, nomeadamente, uma particular atenção à educação permanente e de adultos.

2.7 A gestão estratégica da qualidade educativa implica o desenvolvimento de processos de informação e comunicação e o aumento da visibilidade do sistema, reconhecendo-se, assim, a necessidade de serem criados sistemas alargados de informação entre instituições, serviços e públicos no domínio das políticas educativas, por forma a criar as condições que permitam a mobilização da opinião pública para a importância da educação.

2.8 A credibilização do sistema educativo e da escola é imprescindível, associando aos objectivos de alargamento da escolaridade objectivos de qualidade, investimento sustentado e rigor.

\section{OBJECTIVOS ESTRATÉGICOS}

No desenvolvimento dos princípios gerais enunciados, o PACTO EDUCATIVO PARA O FUTURO deve visar a prossecução dos seguintes objectivos estratégicos:

3.1 Promover a participação social no desenvolvimento do sistema educativo, o que implica:

3.1.1 Redefinir o papel do Estado, favorecendo uma maior participação das diversas forças sociais nas decisões e na execução de políticas educativas, em todos os níveis da administração, sem prejuízo da autonomia técnica e profissional dos agentes educativos. 
3.1.2 Criar e desenvolver estruturas de participação formal na administração do sistema educativo e das escolas.

3.1.3 Desenvolver mecanismos de apoio e incentivo à intervenção dos pais e das suas associações.

3.2 Modernizar, regionalizar e descentralizar a administração do sistema educativo, visando, designadamente:

3.2.1 Assegurar um equilíbrio dinâmico entre, por um lado, as funções centrais de concepção, arbitragem, regulação e identificação/correcção das assimetrias internas do sistema e, por outro, o desenvolvimento de projectos diversificados de cada território e comunidade educativa.

3.2.2 Transferir competências, recursos e meios para os órgãos de poder local e para as escolas.

3.2.3 Promover incentivos ao mérito e ao desempenho de qualidade, valorizando o primado da dimensão educativa sobre a dimensão meramente administrativa.

3.2.4 Desburocratizar o funcionamento dos serviços, adoptando políticas de modernização da gestão e de formação do pessoal.

3.3 Desenvolver processos de informação estratégica e alargar as redes de comunicação, o que pressupõe, entre outros aspectos:

3.3.1 Definir uma política e montar dispositivos de informação que aumentem a visibilidade do sistema e mobilizem a opinião pública para as questões educativas.

3.3.2 Contribuir para a especialização da comunicação social no domínio da educação.

3.3.3 Melhorar a imagem pública da escola e da função educativa.

3.4 Fazer do sistema educativo um sistema de escolas, e de cada escola um elo de um sistema local de formação, no sentido de:

3.4.1 Colocar a escola no centro das preocupações e do interesse da população portuguesa a todos os níveis. 
3.4.2 Territorializar as políticas educativas dinamizando e apoiando formas diversificadas de gestão integrada de recursos e favorecendo a sua adaptação às especificidades locais.

3.4.3 Desenvolver os níveis de autonomia das escolas.

3.4.4 Privilegiar as funções de acompanhamento e apoio técnico às escolas, designadamente no âmbito do ensino básico.

3.5 Promover a educação e a formação como um processo permanente ao longo de toda a vida, procurando, entre outros aspectos:

3.5.1 Articular os vários níveis do sistema escolar com actividades formais e informais de educação e formação profissional.

3.5.2 Desenvolver oportunidades e ofertas de formação contínua, recorrente e em alternância.

3.5.3 Intervir, a partir do sistema educativo e das práticas educativas não formais, sobre a formação cívica e cultural da população, favorecendo a afirmação de uma consciência política democrática, um entendimento das diferenças entre culturas e o diálogo multi/intercultural e uma nova atitude face aos media.

3.6 Garantir a universalização da educação básica de qualidade, o que implica, designadamente:

3.6.1 Conferir prioridade à educação pré-escolar e ao ensino básico e, dentro deste, ao primeiro ciclo, enquanto alicerces da qualidade da educação e garantia da formação integral das crianças e dos jovens.

3.6.2 Assegurar níveis de escolaridade básica sucedida para todos os alunos.

3.6.3 Promover a integração escolar, social e cultural dos alunos. 
3.6.4 Definir denominadores comuns quanto a currículos, dispositivos pedagógicos e padrões de avaliação e certificação, segundo o modelo de uma escolaridade básica única, mas não uniforme, conferindo espaços de autonomia às escolas para encontrarem as suas próprias soluções.

3.7 Consagrar um novo lugar e uma nova finalidade para o ensino secundário, para o que se afigura necessário:

3.7.1 Assumir a dupla natureza do ensino secundário: como ciclo intermédio de prosseguimento de estudos e como ciclo de formação terminal.

3.7.2 Reconhecer a diversidade de vias de ensino e formação sempre qualificantes, respeitando a sua especificidade, definindo princípios de equivalência geral de certificação e promovendo modos de interacção entre as vias de ensino regular e o ensino profissional.

3.8 Promover o desenvolvimento equilibrado do ensino superior, o que pressupõe, designadamente:

3.8.1 Alargar a oferta de ensino superior público, assegurando, desse modo, a liberdade de escolha entre ensino público e ensino particular e cooperativo.

3.8.2 Reforçar os níveis de qualidade e rigor, quer através de mecanismos de avaliação independente da qualidade do sistema, quer pelo acompanhamento regular das saídas profissionais dos diplomados.

3.8.3 Reequacionar a problemática do financiamento do ensino superior, da comparticipação dos utentes nos seus custos e do apoio social.

3.9 Valorizar, dignificar e responsabilizar os profissionais da educação, o que pressupõe, entre outros aspectos:

3.9.1 Reconhecer o papel essencial e insubstituível dos educadores e dos professores para a melhoria da qualidade do ensino e das aprendizagens.

3.9.2 Dignificar a carreira docente, associando uma nova valorização a uma acrescida responsabilização dos profissionais pelas funções educativas. 
3.9.3 Aliar a promoção da diversificação de perfis profissionais e a especialização dos agentes educativos ao desenvolvimento de capacidades mais amplas e interdisciplinares de intervenção docente.

3.9.4 Institucionalizar incentivos ao mérito e ao desempenho de qualidade dos agentes educativos.

\section{DEZ COMPROMISSOS DE ACÇÃO}

A concretização dos objectivos estratégicos que informam o PACTO EDUCATIVO PARA O FUTURO deve traduzir-se na identificação dos principais protagonistas da negociação e das áreas prioritárias de intervenção, segundo uma lógica de geometria variável. Para o Governo, tal concretização passa pela assunção imediata de dez compromissos para a acção.

4.1 Descentralizar as políticas educativas e transferir competências para os órgãos de Poder Local.

Protagonistas: Ministério da Educação, Ministério do Planeamento e da Administração do Território e órgãos representativos do poder local, nomeadamente a Associação Nacional de Municípios Portugueses.

\section{Acções prioritárias}

- Lançamento do processo de reordenamento territorial dos níveis de intervenção pública na gestão da rede escolar.

- Conclusão, no prazo da legislatura, do processo de transferência de poderes e de competências para os órgãos de poder local no domínio das infra-estruturas, da acção social, da coordenação intersectorial de níveis e modalidades de formação, de animação socioeducativa e de complemento curricular, no âmbito da educação pré-escolar e do ensino básico.

- Dinamização da constituição de Conselhos Locais de Educação. 
4.2 Fazer da Escola o centro privilegiado das políticas educativas. Protagonistas: Ministério da Educação, Ministério da Saúde, Ministério da Justiça, Ministério da Administração Interna, Secretarias de Estado da Juventude e do Desporto, órgãos de administração, direcção e gestão de escolas, associações de pais, órgãos de poder local, sindicatos de professores, centros de formação de associações de escolas.

\section{Acções prioritárias}

- $\quad$ Aprovação das linhas de orientação estratégica para o desenvolvimento de processos de autonomia das escolas, até final do primeiro semestre de 1996.

- $\quad$ Celebração de contratos de autonomia entre as escolas e o Ministério da Educação, apoiando o desenvolvimento de formas diversificadas de organização pedagógica e administrativa, respeitando a autonomia de cada instituição e a especificidade de cada território educativo.

- Aperfeiçoamento dos modelos de gestão escolar que favoreçam a participação dos professores, dos pais, dos estudantes e das instituições locais na direcção dos estabelecimentos de ensino, com institucionalização de mecanismos de protecção ao «voluntariado social» que possibilitem a efectiva participação dos pais na educação dos filhos e na vida das escolas.

- $\quad$ Adopção de medidas, no prazo da legislatura, visando a humanização e melhoria do ambiente educativo das instituições escolares, promovendo, designadamente, a melhoria das condições físicas, morais e sociais de desenvolvimento das escolas de ensino, quer em termos de equipamentos e recursos, quer em termos de segurança e convivialidade.

- Desenvolvimento de um programa visando garantir a segurança das instalações escolares, integrando intervenções específicas de prevenção e combate à violência, à droga, ao álcool e ao tabaco e de promoção da formação cívica.

- Desenvolvimento de medidas de reforço do policiamento dos acessos e das zonas circundantes dos estabelecimentos de educação e de ensino. 
4.3 Criar uma rede nacional de Educação Pré-Escolar. Protagonistas: Ministério da Educação, Ministério da Solidariedade e da Segurança Social, Ministério da Saúde, Associação Nacional de Municípios Portugueses, instituições particulares de solidariedade social, entidades responsáveis pelo ensino particular e cooperativo, sindicatos de professores, personalidades de reconhecido mérito.

\section{Acções prioritárias}

- $\quad$ Aprovação do quadro normativo orientador da educação pré-escolar, até final do mês de Abril, com posterior envio para apreciação pelo Conselho Nacional de Educação.

- $\quad$ Generalização da educação pré-escolar, segundo modalidades diversificadas em função da especificidade dos contextos, com abertura das salas de educação préescolar que reúnam condições de funcionamento a partir do ano lectivo 1996/1997.

4.4 Melhorar a qualidade do processo educativo.

Protagonistas: Ministério da Educação, Ministério das Finanças, Ministério do Planeamento e da Administração do Território, Ministério da Ciência e da Tecnologia, Ministério da Cultura, Ministério do Ambiente, escolas, institutos de investigação, grandes fundações, sociedades científicas e pedagógicas, associações culturais, associações de defesa do património, associações ecologistas, personalidades de reconhecido mérito.

\section{Acções prioritárias}

- $\quad$ Lançamento de um programa de divulgação e promoção da inovação e da qualidade educativa, valorizando e divulgando as experiências positivas realizadas pelas escolas, apoiando e acompanhando processos tendentes à construção de escolas de qualidade e criando sistemas de incentivos ao desenvolvimento de processos de inovação e de mudança. 
- Desenvolvimento de medidas, com impacto no ano lectivo em curso e seguintes, visando a promoção das aprendizagens e o sucesso de uma escolaridade para todos os alunos, designadamente ao nível da educação básica, em articulação com o reforço do apoio educativo para crianças e jovens com necessidades educativas especiais.

- Lançamento de um programa piloto no domínio do ensino experimental, com reforço dos recursos laboratoriais e dos equipamentos das escolas e desenvolvimento de acções de formação de professores, abrangendo estabelecimentos dos vários níveis de escolaridade.

- $\quad$ Desenvolvimento de um programa de modernização da administração do sistema educativo nos domínios do «planeamento estratégico», do "acompanhamento», da "auditoria» e «consultoria» às escolas, na avaliação externa e monitorização do funcionamento do sistema e das escolas.

- $\quad$ Adopção de medidas, no decurso da legislatura, designadamente em sede de revisão da reforma curricular dos ensinos básico e secundário, tendentes a promover as dimensões artística, cultural e ambiental da educação.

- Desenvolvimento de acções tendentes a favorecer a formação pessoal e social das crianças e dos jovens, designadamente nos domínios da educação para a cidadania e para o reforço da identidade nacional, para a solidariedade e para os valores democráticos e da dimensão europeia na educação.

4.5 Assegurar a educação e a formação como um processo permanente ao longo de toda a vida. Protagonistas: Ministério da Educação, Ministério para a Qualificação e o Emprego, Ministério do Ambiente, Ministério da Cultura, Ministério da Solidariedade e da Segurança Social, órgãos do poder local, associações locais. 


\section{Acções prioritárias}

- Lançamento de um programa, no primeiro trimestre de 1996 e no âmbito do Ano Internacional da Educação e da Formação para Toda a Vida, tendente a assegurar a actualização permanente dos níveis de educação/formação da população em geral e, em especial, daquela que vai sendo marginalizada à medida e na medida em que os níveis de escolaridade básica avançam.

- $\quad$ Adopção de medidas visando estimular a actualização, ao longo de toda a vida, do saber, do saber-fazer, do «aprender a ser com os outros» e do saber relacional e comportamental de toda a população, em especial dos indivíduos e dos grupos marcados por processos de exclusão social.

4.6 Assegurar a formação para a vida activa e a relação entre educação-formação. Protagonistas: Ministério da Educação, Ministério para a Qualificação e o Emprego, Ministério da Solidariedade e Segurança Social, Ministério da Economia, Associação Nacional de Municípios Portugueses, confederações patronais e confederações sindicais, associações de pais, associações de estudantes.

\section{Acções prioritárias}

- $\quad$ Lançamento de cursos de formação profissional para os jovens que concluíram a escolaridade obrigatória.

- Diversificação de vias de educação/formação no ensino secundário, sempre certificantes e qualificantes.

- Lançamento de modalidades específicas de educação/ formação para os jovens que tenham abandonado a escola antes da conclusão da escolaridade obrigatória.

- Desenvolvimento, no decurso da legislatura, de uma política integrada de formação inicial de jovens que garanta a articulação dos vários subsistemas existentes dependentes de diferentes tutelas, designadamente o sistema de aprendizagem, os cursos tecnológicos do ensino secundário, as escolas profissionais, as escolas tecnológicas, a formação profissional pós-escolaridade básica. 
- Desenvolvimento de políticas integradas que favoreçam e intensifiquem a articulação Escola / Empresa.

4.7 Valorizar e dignificar o papel dos professores e dos educadores. Protagonistas: Ministério da Educação, Ministério da Ciência e da Tecnologia, Ministério das Finanças, Secretaria de Estado da Administração Pública, sindicatos de professores, associações pedagógicas de professores, centros de formação de associações de escolas, instituições de ensino superior, associações científicas e pedagógicas, personalidades de reconhecido mérito.

\section{Acções prioritárias}

- $\quad$ Renegociação dos estatutos das carreiras docentes, associando uma nova valorização a uma acrescida responsabilização, garantindo condições de acesso à formação contínua e instituindo mecanismos de avaliação e diferenciação interna que tenham como referência a qualidade do respectivo desempenho profissional.

- Aprovação do novo regime jurídico da formação contínua de professores.

- Redefinição, no prazo da legislatura, do sistema de colocação de professores do ensino não superior visando a estabilidade do corpo docente, designadamente privilegiando as colocações plurianuais, tomando como referência a duração dos ciclos de escolaridade, e desenvolvendo incentivos à fixação de professores em zonas isoladas.

- $\quad$ Revisão dos perfis profissionais dos professores, promovendo a diversificação e a especialização, associadas a uma maior e mais alargada competência pedagógica, no sentido da interdisciplinaridade e integração dos saberes.

4.8 Reequacionar os sistemas de financiamento da educação, considerando, designadamente: 
4.8.1 O financiamento da escolaridade obrigatória no sentido da gratuidade. Protagonistas: Ministério da Educação, Ministério das Finanças, Ministério da Solidariedade e Segurança Social, Associação Nacional de Municípios Portugueses, Confederação Nacional das Associações de Pais.

4.8.2 O financiamento do ensino secundário, que deve admitir soluções diversificadas. Protagonistas: Ministério da Educação, Ministério das Finanças, Ministério para a Qualificação e o Emprego, Associação Nacional das Escolas Profissionais, Confederação Nacional das Associações de Pais, associações de estudantes.

4.8.3 O financiamento do ensino superior, considerando quer os aspectos de funcionamento, investimento, incentivos e contratos-programa, quer as problemáticas da acção social escolar e das propinas. Protagonistas: Ministério da Educação, Ministério das Finanças, Ministério para a Qualificação e o Emprego, Ministério da Ciência e da Tecnologia, Conselho de Reitores das Universidades Portuguesas, Conselho Coordenador do Ensino Superior Politécnico, associações de estudantes, Confederação Nacional das Associações de Pais.

\section{Acções prioritárias}

- Aprovação do regime jurídico de delimitação de competências da administração central, regional e local.

- $\quad$ Aprovação do modelo de financiamento do ensino superior, criando mecanismos de repartição de custos e consagrando medidas de apoio social aos estudantes carenciados.

4.9 Promover o desenvolvimento equilibrado do ensino superior. Protagonistas: Ministério da Educação, Ministério da Economia, Ministério para a Qualificação e o Emprego, Ministério da Ciência e da Tecnologia, Ministério do Planeamento e da Administração do Território, Conselho de Reitores das Universidades Portuguesas, Conselho Coordenador do Ensino Superior Politécnico, associações de estudantes, Confederação Nacional das Associações de Pais. 


\section{Acções prioritárias}

- $\quad$ Revisão do regime de acesso ao ensino superior, reduzindo o número excessivo e mesmo redundante de provas a que os estudantes vêm sendo submetidos.

- $\quad$ Aumento progressivo, no decurso da legislatura, do número de vagas oferecidas pelo ensino público, designadamente nos cursos de componente científico-tecnológica, assegurando, desse modo, a liberdade de escolha entre ensino público e ensino particular e cooperativo.

- Revisão do sistema de articulação entre o ensino superior universitário e politécnico, por forma a construir um novo equilíbrio na relação entre longa e curta duração de estudos de graduação.

4.10 Valorizar e dignificar o papel e a inserção do ensino particular e cooperativo no Sistema Educativo. Protagonistas: Ministério da Educação, Ministério das Finanças, Ministério da Solidariedade e Segurança Social, entidades responsáveis pelo ensino particular e cooperativo, instituições particulares de solidariedade social, órgãos do poder local.

\section{Acções prioritárias}

- Reactivação dos trabalhos do Conselho Coordenador do Ensino Particular e Cooperativo.

- $\quad$ Revisão do Estatuto do Ensino Particular e Cooperativo dos ensinos superior e não superior.

- Desenvolvimento dos trabalhos tendentes à definição de cartas escolares integradas, que articulem a intervenção do ensino público e do ensino particular e cooperativo, no âmbito da educação pré-escolar e dos ensinos básico, secundário e superior. 


\title{
Contactar
}

Revista lberoamericana de Educación

\author{
Principal OEI
}

